\title{
Strafrecht
}

\section{Brexit en strafrechtelijke samenwerking: de gevolgen van het perspectief van vertrek uit de Unie voor de tenuitvoerlegging van een} $\mathrm{EAB}$

\author{
Mr. dr. M.K. Bulterman*
}

Op 29 maart 2017 heeft het Verenigd Koninkrijk kennisgegeven op grond van artikel 50 lid 2 VEU van het voornemen tot terugtrekking uit de Europese Unie. Welke gevolgen heeft deze kennisgeving voor de beoordeling van een door de autoriteiten van het Verenigd Koninkrijk uitgevaardigd Europees Aanhoudingsbevel op grond van Kaderbesluit 2002/584 betreffende het Europees aanhoudingsbevel en de procedures van overlevering tussen de lidstaten? Op deze vraag geeft het Hof van Justitie een antwoord in het arrest $R O$ van 19 september 2018, dat centraal staat in deze bijdrage.

Hvf 19 september 2018, zaak C-327/18 PPU, RO, ECLI:EU:C:2018:733

\section{Inleiding}

Enkele weken voor het bereiken van de 'Brexit-dag' van 29 maart 2019 is de uitkomst van het 'Brexit-proces' nog steeds onzeker. Sinds de kennisgeving op grond van artikel 50 lid 2 VEU van het voornemen tot terugtrekking uit de Europese Unie van het Verenigd Koninkrijk op 29 maart 2017 begeven we ons niet alleen vanuit politiek perspectief op onbekend terrein. Het 'Brexitproces' heeft ook allerlei nieuwe Europeesrechtelijke vragen opgeworpen. Een voorbeeld hiervan is de vraag die centraal staat in het arrest $R O$ dat in deze bijdrage besproken wordt: welke gevolgen heeft de kennisgeving op grond van artikel 50 lid 2 VEU voor de beoordeling van een door de autoriteiten van het Verenigd Koninkrijk uitgevaardigd Europees Aanhoudingsbevel (EAB)

Mr. dr. M.K. (Mielle) Bulterman is hoofd van de afdeling Europees recht, Directie Juridische Zaken, van het ministerie van Buitenlandse zaken. Deze bijdrage is geschreven op persoonlijke titel. op grond van Kaderbesluit 2002/584 betreffende het Europees aanhoudingsbevel en de procedures van overlevering tussen de lidstaten ${ }^{1}$ (hierna: kaderbesluit)?

\section{Feiten en het geschil voor de lerse rechter}

Tegen de heer RO zijn door de rechterlijke instanties van het Verenigd Koninkrijk twee EAB's uitgevaardigd waarbij zijn overlevering wordt verzocht met het oog op strafvervolging. RO verzet zich tegen zijn overlevering voor de Ierse High Court. Hij beroept zich daarbij onder meer op de terugtrekking van het Verenigd Koninkrijk uit de Unie. Ook doet hij een beroep op artikel 3 EVRM vanwege de detentieomstandigheden die hem te wachten zouden staan in de gevangenis van Maghaberry (Noord-Ierland), ${ }^{2}$ waarin hij na overlevering zou belanden. Vanwege deze laatste claim heeft de High Court, conform het arrest Aranyosi, ${ }^{3}$ de autoriteiten van het Verenigd Koninkrijk om nadere inlichtingen gevraagd. De hierop gegeven reactie heeft de zorgen van de Ierse High Court dat RO in de gevangenis van Maghaberry onmenselijk zou worden behandeld weggenomen. De High Court heeft daarom de door RO tegen zijn overlevering aangevoerde bezwaren afgewezen, met uitzondering van de relevantie van Brexit.

1. PbEU 2002, L 190/1, zoals gewijzigd bij kaderbesluit 2009/299/JBZ van de Raad van 26 februari 2009, PbEU 2009, L 81/24.

2. In het arrest van het Hof van Justitie wordt niet uitgeweid over de specifieke omstandigheden in de Maghaberrygevangenis. Zie voor een recente beschrijving hiervan het rapport van het Comité voor de Preventie van Foltering en Onmenselijke of Vernederde Behandeling of Bestraffing (CPT) van de Raad van Europa van 6 december 2018 (CPT/Inf (2018) 47, https://rm.coe.int/16808ff5f2.

3. HvJ 5 april 2016, gevoegde zaken C-404/15 en C-659/15 PPU, Aranyosi en Căldăraru, ECLI:EU:C:2016:198. 
In dat verband wijst de Ierse High Court erop dat de kennisgeving op grond van artikel 50 lid 2 VEU leidt tot de terugtrekking van het Verenigd Koninkrijk uit de Unie vanaf 29 maart 2019. In geval van overlevering zal RO na die datum zeer waarschijnlijk nog steeds in het Verenigd Koninkrijk zijn gedetineerd. Het is onzeker welke regels dan de strafrechtelijke samenwerking tussen de Unie en het Verenigd Koninkrijk zullen beheersen. De High Court vraagt zich daarom af of hij de tenuitvoerlegging van het EAB moet weigeren of uitstellen in afwachting van nadere duidelijkheid hierover. Met name de volgende vier aspecten van overlevering onder het Unierecht zijn daarbij van belang: het recht op verrekening van de periode van vrijheidsbeneming in de uitvoerende lidstaat overeenkomstig artikel 26 van het kaderbesluit, het zogenoemde 'specialiteitsbeginsel' als bedoeld in artikel 27 van het kaderbesluit, het recht waardoor de verdere overlevering of uitlevering wordt beperkt als bedoeld in artikel 28 van het kaderbesluit, en de eerbiediging van de grondrechten in overeenstemming met het Handvest van de grondrechten van de Europese Unie (hierna: het Handvest). Ook vraagt de High Court of het bezwaarlijk is dat na de daadwerkelijke terugtrekking het Hof van Justitie geen rechtsmacht meer heeft om prejudiciële vragen uit het Verenigd Koninkrijk over het kaderbesluit te beantwoorden.

\section{Het arrest van het Hof van}

\section{Justitie}

Het Hof van Justitie bevestigt in zijn uitspraak het uitgangspunt dat de tenuitvoerlegging van een EAB alleen kan worden geweigerd op basis van de limitatief in het kaderbesluit opgesomde weigeringsgronden. Wel kunnen de beginselen van wederzijdse erkenning en wederzijds vertrouwen waarop het kaderbesluit is gebaseerd 'in uitzonderlijke omstandigheden' worden beperkt. ${ }^{4}$ Dat is bijvoorbeeld het geval indien overlevering tot een onmenselijke of vernederende behandeling in de zin van artikel 4 van het Handvest kan leiden. ${ }^{5}$ In zo'n situatie dient de uitvoerende rechterlijke autoriteit - zoals de Ierse High Court ook heeft gedaan - de uitvaardigende rechterlijke autoriteit om alle aanvullende informatie te vragen die noodzakelijk is om te beoordelen of van een dergelijk gevaar sprake is. ${ }^{6}$

Wat betreft de relevantie van de kennisgeving van het voornemen van een lidstaat om zich overeenkomstig artikel $50 \mathrm{VEU}$ uit de Unie terug te trekken, merkt het Hof van Justitie op dat zo'n kennisgeving er niet toe leidt dat de toepassing van het Unierecht wordt opgeschort. Het Unierecht blijft onverkort van kracht tot de

4. Aranyosi en Căldăraru, punt 82, en HvJ 25 juli 2018, zaak C-216/18 PPU, Minister for Justice and Equality (Gebreken in het gerechtelijk apparaat), ECLI:EU:C:2018:586, punt 43.

5. Aranyosi en Căldăraru, punt 104, en Minister for Justice and Equality (Gebreken in het gerechtelijk apparaat), punt 44.

6. Minister for Justice and Equality (Gebreken in het gerechtelijk apparaat), punt 76 . daadwerkelijke terugtrekking. Artikel 50 regelt immers de procedure van terugtrekking en bepaalt onder meer dat de daadwerkelijke terugtrekking plaatsvindt op de datum van inwerkingtreding van een tussen de EU en de vertrekkende lidstaat gesloten terugtrekkingsakkoord, of - indien een dergelijk akkoord niet tot stand komt twee jaar na de kennisgeving aan de Europese Raad. De weigering om voor die datum een $\mathrm{EAB}$ ten uitvoer te leggen zou leiden tot een eenzijdige opschorting van de bepalingen van het kaderbesluit. Uit overweging 10 van het kaderbesluit volgt echter dat opschorting van de toepassing van het kaderbesluit alleen aan de orde is wanneer de Europese Raad constateert dat in de uitvaardigende lidstaat de in artikel 2 VEU neergelegde beginselen worden geschonden. Het gegeven dat een lidstaat een kennisgeving heeft gedaan op grond van artikel 50 lid 2 VEU van het voornemen tot terugtrekking uit de Europese Unie kan op zichzelf dan ook niet worden aangemerkt als een uitzonderlijke omstandigheid, die kan rechtvaardigen dat de tenuitvoerlegging van een door die lidstaat uitgevaardigd Europees aanhoudingsbevel wordt geweigerd.

Dat betekent echter niet dat een dergelijke kennisgeving zonder betekenis is. De uitvoerende rechter dient wel te onderzoeken of de rechten die aan het Kaderbesluit worden ontleend ook na het daadwerkelijke vertrek uit de Unie zijn gewaarborgd. In dat verband merkt het Hof van Justitie op dat het Verenigd Koninkrijk partij is bij het EVRM en de bepalingen daarvan heeft overgenomen in zijn nationale recht. Het besluit om zich terug te trekken uit de Unie heeft geen invloed op de verplichting van het Verenigd Koninkrijk om artikel 3 EVRM - waarmee artikel 4 van het Handvest overeenkomt - na te leven. Wat betreft het specialiteitsbeginsel uit artikel 27 van het kaderbesluit merkt het Hof van Justitie op dat een persoon zich na zijn overlevering voor de rechters van de uitvaardigende lidstaat op dit beginsel moet kunnen beroepen. Er is echter geen geding over dit beginsel in de uitvaardigende lidstaat aanhangig en er zijn ook geen tastbare aanwijzingen dat een geding hierover wordt overwogen. Hetzelfde geldt voor de in artikel 28 van het kaderbesluit bedoelde beperkingen aan de verdere overlevering of uitlevering aan een andere lidstaat. Voorts weerspiegelen deze bepalingen van het kaderbesluit artikel 14 en artikel 15 van het Europees Verdrag betreffende uitlevering van de Raad van Europa van 13 december 1957. Het Verenigd Koninkrijk heeft dit verdrag geratificeerd en omgezet in zijn nationale recht. Deze rechten vallen dus onder de nationale wetgeving. Ook de verplichting tot verrekening van de periode van vrijheidsbeneming in de uitvoerende lidstaat overeenkomstig artikel 26 van het kaderbesluit is opgenomen in het nationale recht. Deze verplichting past het Verenigd Koninkrijk los van het Unierecht toe op iedere overgeleverde persoon op zijn grondgebied. Het Hof van Justitie concludeert dat de rechten die voortvloeien uit de artikelen 26 tot en met 28 van het kaderbesluit en uit artikel 4 van het Handvest - niet alleen bij overlevering maar ook bij uitlevering - worden beschermd door nationaalrechtelijke bepalingen, zodat 
zij niet afhangen van de toepassing van het kaderbesluit in het Verenigd Koninkrijk. Er zijn dus geen tastbare aanwijzingen dat RO na de terugtrekking van het Verenigd Koninkrijk de mogelijkheid zal worden ontnomen om die rechten in te roepen voor de nationale rechter. Het gegeven dat de nationale rechter na de terugtrekking van het Verenigd Koninkrijk uit de Unie - bij gebreke van een akkoord tussen deze lidstaat en de Unie ter zake - hierover geen prejudiciële vraag kan stellen, maakt dit niet anders. Daarbij herinnert het Hof van Justitie eraan dat het pas op 1 december 2014 volledige rechtsmacht heeft verkregen om het kaderbesluit uit te leggen, terwijl dit besluit sinds 1 januari 2004 in de lidstaten moet worden toegepast.

\section{Commentaar}

\section{Kennisgeving van vertrek geen aantasting van wederzijds vertrouwen}

Het beginsel van wederzijds vertrouwen vereist dat elke lidstaat ervan uitgaat dat de andere lidstaten het Unierecht, met inbegrip van de grondrechten uit het Handvest, in acht nemen. ${ }^{7}$ Dit beginsel is cruciaal voor het goede functioneren van met name de instrumenten die tot stand zijn gebracht in het kader van de ruimte van vrijheid, veiligheid en recht. Daaronder valt het kaderbesluit dat aan de orde is in de zaak $R O$ als onderdeel van de strafrechtelijke samenwerking, maar ook de EUrechtelijke instrumenten die de samenwerking in burgerlijke zaken en op het terrein van asiel en migratie betreffen.

In zeer uitzonderlijke omstandigheden kunnen de beginselen van wederzijds vertrouwen en wederzijdse erkenning echter worden beperkt, zo volgt uit de vaste rechtspraak van het Hof van Justitie. ${ }^{8}$ De kennisgeving van een lidstaat dat hij het voornemen heeft uit de Unie te vertrekken onder artikel $50 \mathrm{VEU}$ is volgens het Hof van Justitie op zichzelf geen dergelijke omstandigheid. In de periode na kennisgeving tot het daadwerkelijke vertrek uit de Unie verandert volgens het Hof van Justitie de positie van lidstaat onder het Unierecht niet: ${ }^{9}$ het Unierecht blijft voor de lidstaat in die periode onverkort van kracht. En dat geldt dus ook voor de beginselen van wederzijds vertrouwen en wederzijdse erkenning waarop het systeem van overlevering van het kaderbesluit is gebaseerd. ${ }^{10}$ Dit element van het arrest is op zich weinig verrassend en ook niet doorslaggevend voor de beoordeling van het EAB door de Ierse rechter. Indien de Ierse rechter RO overlevert heeft dat immers gevolgen die

7. HvJ 19 september 2018, zaak C-327/18 PPU, RO, ECLI:EU:C: 2018:733, punt 35

8. $R O$, punt 39 .

9. De enige uitzondering hierop volgt uit art. 50 lid 4 VEU, waarin is bepaald dat bij de beraadslagingen over besluitvorming van de Raad en de Europese Raad op grond van art. 50 VEU (zoals het sluiten van het terugtrekkingsakkoord namens de Unie) de terugtrekkende lidstaat niet deelneemt. Zie HvJ 10 december 2018, zaak C-621/18, Wightman, ECLI:EU:C:2018:999, punt 73

10. $R O$, punt 48 . zich waarschijnlijk uitstrekken tot ná het daadwerkelijke vertrek van het Verenigd Koninkrijk uit de Unie. In hoeverre en op welke wijze dient de Ierse rechter met dat perspectief rekening te houden? Daarop zal nu worden ingegaan.

\section{Het perspectief van vertrek}

Volgens het Hof van Justitie dient de uitvoerende rechter te onderzoeken of de rechten die de over te leveren persoon aan het Unierecht ontleent, hem worden ontnomen na de daadwerkelijke terugtrekking van de lidstaat uit de Unie. ${ }^{11}$ De noodzaak om tot deze beoordeling over te gaan wordt door het Hof van Justitie niet expliciet benoemd. Drie uitgangspunten lijken hieraan ten grondslag te liggen. Allereerst vereist het Unierecht dat de over te leveren persoon de materiële bescherming van het Unierecht behoudt, ook nadat de lidstaat waarnaar hij wordt overgeleverd de Unie heeft verlaten. Ten tweede is van belang dat deze bescherming na het vertrek niet langer wordt geboden door het Unierecht. De terugtrekking heeft immers tot gevolg dat een einde komt aan de verplichtingen van de lidstaat onder het Unierecht. Daarom moet worden onderzocht in hoeverre de materiële bescherming die het Unierecht biedt na terugtrekking op andere wijze dan via het Unierecht wordt gewaarborgd. Wat betreft het kaderbesluit is daarbij relevant dat het EVRM, het Europees Verdrag betreffende uitlevering van de Raad van Europa en de nationale wetgeving ter uitvoering van deze verdragen in het Verenigd Koninkrijk eenzelfde bescherming bieden. Ten derde is van belang dat - hoewel met het vertrek uit de Unie ook een einde komt aan de toepasselijkheid van de Unierechtelijke beginselen van wederzijds vertrouwen en wederzijds erkenning - ook in de verhouding met derde landen dient te worden uitgegaan van de naleving te goeder trouw van de geldende verplichtingen. Dit komt expliciet naar voren in punt 61 van het arrest. Daarin verwijst het Hof van Justitie naar punt 70 van de conclusie van advocaat-generaal Szpunar. Dit luidt als volgt:

'(...) bij de tenuitvoerlegging van het EAB kunnen de rechterlijke autoriteiten van de uitvoerende lidstaat aannemen dat de uitvaardigende lidstaat, wat betreft de persoon die daadwerkelijk wordt overgeleverd, de inhoud van het kaderbesluit ten gronde zal naleven, zulks ook in situaties na de overlevering die zich voordoen nadat deze lidstaat de Unie heeft verlaten. Een dergelijk vermoeden is gerechtvaardigd indien andere internationale instrumenten van toepassing zullen blijven op de lidstaat die de Unie heeft verlaten. Slechts ingeval tastbare elementen het bewijs vormen van het tegendeel, mogen de rechterlijke autoriteiten van een lidstaat beslissen het aanhoudingsmandaat niet ten uitvoer te leggen.'

Een belangrijk argument voor de advocaat-generaal om tot dit criterium te komen is dat hiermee wordt aange-

11. $R O$, punt 49 
sloten bij het criterium dat het Hof van Justitie heeft toegepast in zaken die de uitlevering van een Unieburger naar een derde land betroffen. ${ }^{12}$ Het zou volgens hem niet coherent zijn om bij overlevering (naar een andere EU-lidstaat) een strikter criterium te hanteren dan bij uitlevering (naar een derde land). Vanuit dat perspectief beschouwd is het ook niet opmerkelijk dat het wegvallen van de rechtsmacht van het Hof van Justitie na terugtrekking - zowel volgens de advocaat-generaal als het Hof van Justitie - als zodanig geen grond vormt om overlevering te weigeren. Bij uitlevering aan een derde land komt de betrokken persoon immers ook in de situatie terecht dat het Hof van Justitie geen enkele rol heeft bij het waarborgen van zijn rechten.

Het 'bagatelliseren' van het wegvallen van de mogelijkheid om prejudiciële vragen te stellen is desalniettemin interessant. Een essentieel onderdeel van het Unierecht is immers het op de samenwerking tussen de nationale rechter en het Hof van Justitie gebaseerde stelsel van rechtsbescherming. In arresten als Advies 2/13, Achmea en Associação Sindical dos Fuizes Portugueses ${ }^{13}$ heeft het Hof van Justitie steeds het belang benadrukt van het goede functioneren van deze samenwerking voor het waarborgen van de bescherming van de rechten onder het Unierecht. Toch oordeelt het Hof van Justitie in het arrest $R O$ - in navolging van de advocaat-generaal - dat het ontbreken van rechtsmacht van het Hof van Justitie over het kaderbesluit in het Verenigd Koninkrijk postBrexit geen obstakel vormt voor overlevering. Daarbij hechten de advocaat-generaal en het Hof van Justitie belang aan het gegeven dat het Hof van Justitie tot 1 december 2014 geen volledige rechtsmacht had over het kaderbesluit. Maar wat is hiervan precies de relevantie? Dat laat het Hof van Justitie in het midden. Het had ook een meer principiële benadering kunnen kiezen en expliciet kunnen erkennen dat het systeem van de prejudiciële procedure niet essentieel is voor het waarborgen van de materiële rechten van een individu.

De overwegingen van het Hof van Justitie in de zaak $R O$ over de wijze waarop de rechter rekening dient de houden met het toekomstige vertrek van een lidstaat zijn overigens niet alleen relevant voor de tenuitvoerlegging van EAB's in de periode na de kennisgeving van terugtrekking uit de Europese Unie. Zij hebben ook relevantie voor andere instrumenten die in het kader van de ruimte van vrijheid, veiligheid en recht tot stand zijn gekomen. Zo heeft het Hof van Justitie in zijn arrest van 23 januari 2019 in de zaak M.A. e.a. ${ }^{14}$ een vergelijkbaar oordeel gegeven naar aanleiding van vragen van de Ierse rechter over de gevolgen van de kennisgeving van terugtrekking onder de Dublin III-verordening. ${ }^{15}$

12. Conclusie A-G, 7 augustus 2018, bij zaak C-327/18 PPU, RO, ECLI:EU:C:2018:644, punten 68 en 69, met een verwijzing naar HvJ 6 september 2016, zaak C-182/15, Petruhhin, ECLI:EU:C:2017:630, punten 56-58.

13. HvJ 27 februari 2018, zaak C-64/16, Associação Sindical dos Juízes Portugueses, ECLI:EU:C:2018:117, punten 32 en 33.

14. HvJ 23 januari 2019, zaak C-661/17, M.A. e.a., ECLI:EU:C:2019:53, punten 83-85.

15. Verordening (EU) nr. 604/2013 van het Europees Parlement en de Raad van 26 juni 2013 tot vaststelling van de criteria en instrumenten om te

\section{Het $E A B$ en het \\ terugtrekkingsakkoord}

De vragen van de Ierse rechter komen onder meer voort uit de onduidelijkheid over de regeling van de toekomstige betrekkingen tussen de Europese Unie en het Verenigd Koninkrijk. Op het moment van het schrijven van deze bijdrage is nog steeds ongewis of, wanneer en op welke wijze het Verenigd Koninkrijk uit de Europese Unie zal vertrekken. Het Terugtrekkingsakkoord waarover de onderhandelaars van de EU en het Verenigde Koninkrijk op 14 november 2018 overeenstemming hebben bereikt, ${ }^{16}$ lijkt na de desastreuze stemming in het Britse Parlement op 15 januari 2019 in de prullenmand te belanden, al blijft May er vooralsnog aan vasthouden. De kritiek op het Terugtrekkingsakkoord komt van twee kanten. Vanuit het kamp van de hardeline Brexiteers is de kritiek dat de banden met de Unie onder het akkoord te hecht blijven, met name vanwege de zogenoemde backstop, de terugvaloptie om een harde grens tussen Ierland en Noord-Ierland te voorkomen. Vanuit het andere kamp klinkt juist de kritiek dat de politieke afspraken over de toekomstige relatie tussen de EU en het Verenigd Koninkrijk niet ambitieus genoeg zijn.

Het Terugtrekkingsakkoord voorziet voor verschillende terreinen van Europese samenwerking in een overgangsperiode die eindigt op 31 december $2020^{17}$ waarin het Verenigd Koninkrijk na het vertrek uit de Unie nog blijft deelnemen aan deze samenwerking op vergelijkbare wijze als een EU-lidstaat. Dit geldt ook voor het terrein van de rechterlijke samenwerking in strafzaken. Indien het Terugtrekkingsakkoord alsnog in werking zou treden dan zal het Verenigd Koninkrijk dus nog ten minste tot 31 december 2020 aan het systeem van het kaderbesluit deelnemen. In beginsel blijft alles dan nog even bij het oude. Slechts op één punt voorziet het Terugtrekkingsakkoord in een afwijking van het onder het kaderbesluit geldende systeem van overlevering. Artikel 185 van het Terugtrekkingsakkoord voorziet in de mogelijkheid van het introduceren van een additionele weigeringsgrond voor overlevering vanuit een EUlidstaat naar het Verenigd Koninkrijk. Indien een lidstaat redenen aanvoert die verband houden met de fundamentele beginselen van het nationale recht van die lidstaat, kan de Unie verklaren (bij het ratificeren van het terugtrekkingsakkoord) dat de uitvoerende gerechtelijke autoriteiten van die lidstaat kunnen weigeren om

bepalen welke lidstaat verantwoordelijk is voor de behandeling van een verzoek om internationale bescherming dat door een onderdaan van een derde land of een staatloze bij een van de lidstaten wordt ingediend, PbEU 2013, L 180/31.

16. De tekst van de conceptovereenkomst is te vinden op: https://ec. europa.eu/commission/publications/draft-agreement-withdrawal-united -kingdom-great-britain-and-northern-ireland-european-union-andeuropean-atomic-energy-community-agreed-negotiators-level-14november-2018_en.

17. Zie art. 126 van het Terugtrekkingsakkoord. Op grond van art. 132 kan de transitieperiode door het Joint Committee (bestaande uit vertegenwoordigers van de EU en het VK) worden verlengd. 
eigen onderdanen op grond van een $\mathrm{EAB}$ over te leveren aan het Verenigd Koninkrijk. Tot een maand na de ontvangst van de verklaring kan het Verenigd Koninkrijk verklaren dat zijn uitvoerende gerechtelijke autoriteiten kunnen weigeren om eigen onderdanen aan die lidstaat over te leveren. De reden achter de opname van deze bepaling is het gegeven dat er lidstaten zijn, zoals Duitsland, waarin het verbod op uitlevering van eigen onderdanen buiten de Europese Unie grondwettelijk is verankerd. ${ }^{18}$ Indien de Unie namens bijvoorbeeld Duitsland een dergelijke verklaring zou afleggen, komt de vraag op wat dat betekent voor de overlevering vanuit Duitsland van onderdanen vanuit andere EU-lidstaten. In de context van de uitlevering aan derde landen heeft het Hof van Justitie in verschillende zaken uitspraak gedaan over een verschil in behandeling tussen eigen onderdanen en onderdanen van een andere lidstaat bij de uitvoering van een bilaterale uitleveringsverdrag met een derde land. ${ }^{19}$ Het is niet zonder meer evident dat deze rechtspraak onverkort op het Terugtrekkingsakkoord kan worden toegepast. Een belangrijk verschil is dat het Terugtrekkingsakkoord voorziet in een Unierechtelijk samenwerkingsinstrument met het Verenigd Koninkrijk. De rechtspraak van het Hof van Justitie heeft juist betrekking op situaties waarin een dergelijk unierechtelijk instrument ontbreekt en de betrekkingen tussen de lidstaten en het derde land worden beheerst door bilaterale uitleveringsverdragen.

\section{De nieuwe relatie: wordt het uitlevering of overlevering?}

Het is de bedoeling dat gedurende de overgangsperiode waarin het terugtrekkingsakkoord voorziet afspraken worden gemaakt over de toekomstige relatie tussen de Unie en het Verenigd Koninkrijk, vast te leggen in één of meer door de Unie en het Verenigd Koninkrijk te sluiten internationale overeenkomsten. Voorbeelden van vergelijkbare overeenkomsten tussen de EU en een derde land op het terrein van strafrechtelijke samenwerking zijn de overeenkomst betreffende uitlevering tussen de Europese Unie en de Verenigde Staten van Amerika ${ }^{20}$ en de overeenkomst tussen de Europese Unie en de Republiek IJsland en het Koninkrijk Noorwegen betreffende de procedures voor overlevering tussen de lidstaten van de Europese Unie en IJsland en Noorwegen. ${ }^{21}$ Het gebruik in elk van de overeenkomsten van uitlevering respectievelijke overlevering is niet zonder reden. De overeenkomst tussen de Europese Unie en de Verenigde Staten is gebaseerd op het klassieke systeem van uitlevering met een rol voor de ministers van justi- tie. ${ }^{22}$ De overeenkomst met IJsland en Noorwegen, die overigens nog niet in werking is getreden, voorziet daarentegen in een samenwerking die vergelijkbaar is met het systeem van het kaderbesluit en die is gebaseerd op een samenwerking tussen gerechtelijke autoriteiten. Een vergelijkbare regeling tussen de Europese Unie en het Verenigd Koninkrijk ligt voor de hand, althans indien beide partijen hun toekomstige strafrechtelijke samenwerking zo veel mogelijk willen laten aansluiten bij de huidige samenwerking op basis van het kaderbesluit. De overeenkomst met IJsland en Noorwegen voorziet net als artikel 185 van het Terugtrekkingsakkoord in de mogelijkheid om overlevering van eigen onderdanen uit te sluiten, op basis van wederkerigheid. Voor het Verenigd Koninkrijk zal verder vooral van belang zijn dat deze overeenkomst geen bepaling bevat die het Hof van Justitie rechtsmacht geeft om vragen uit IJsland en Noorwegen te beantwoorden.

\section{Conclusie}

Per jaar worden zo'n tweehonderd personen vanuit andere lidstaten aan het Verenigd Koninkrijk overgeleverd op basis van het kaderbesluit en worden zo'n duizend personen vanuit het Verenigd Koninkrijk aan andere lidstaten overgeleverd. ${ }^{23}$ Het belang van deelname aan het instrument van het kaderbesluit staat binnen het Verenigd Koninkrijk niet ter discussie. Zo sprak toenmalig Home Secretary Rudd in maart 2017 in het Britse parlement:

'I agree with the principle that the European arrest warrant is an effective tool that is essential to the delivery of effective judgment on the murderers, rapists and paedophiles on whom we have managed to seek judgment. It is a priority for us to ensure that we remain part of the arrangement, and I can reassure Members in all parts of the House that our European partners want to achieve that as well. ${ }^{24}$

Het belang om strafrechtelijke samenwerking tussen de $\mathrm{EU}$ en het Verenigd Koninkrijk in de toekomst voor te zetten is evident, ook voor andere misdrijven dan die door Rudd worden genoemd. Aan de EU-zijde is het enthousiasme over voorzetting van deelname van het Verenigd Koninkrijk aan het systeem van het kaderbesluit na de terugtrekking uit de Unie echter minder groot. Zo sprak Barnier zich in een speech op 19 juni 2018 uitdrukkelijk uit tegen de mogelijkheid dat het Verenigd Koninkrijk aan het kaderbesluit deelneemt wanneer het niet langer het Handvest, de rechtsmacht van het Hof van Justitie en het vrij verkeer van personen
18. S. Bock, 'Brexit and the Future of European Criminal Law: A German Perspective', Criminal Law Forum 2017, 28, p. 311-318.

19. Zie bijvoorbeeld HvJ 6 september 2016, zaak C-182/15, Petruhhin, ECLI:EU:C:2017:630.

20. PbEU 2003, L $181 / 27$

21. PbEU 2006, L 292/2.
22. Zie voor een voorbeeld van toepassing in de Nederlandse rechtspraktijk: Rb. Rotterdam 16 april 2014, ECLI:NL:RBROT:2014:7371.

23. House of Lords, European Union Committee, $6^{\text {th }}$ Report of Session 2017-19, Brexit: judicial oversight of the European Arrest Warrant, p. 5.

24. HC Deb, 6 March 2017, col 550. 
accepteert. $^{25}$ Op het eerste gezicht lijken deze eisen wellicht in tegenspraak met de uitspraak van het Hof in $R O$. Dat is echter niet per se het geval: in $R O$ gaat het om de vraag of de behandeling die RO in Noord-Ierland mogelijk te wachten staat na het vertrek van het Verenigd Koninkrijk uit de Unie een grond vormt om de tenuitvoerlegging van een door de Britse autoriteiten uitgevaardigd $\mathrm{EAB}$ ten uitvoer leggen. Het gaat om de materiële bescherming die het Unierecht aan RO biedt en die ook na het vertrek uit de Unie gewaarborgd dient te blijven. De zaak gaat niet om de vraag in hoeverre en onder welke voorwaarden het mogelijk is dat een derde land aan het systeem van het kaderbesluit deelneemt. Indien het Terugtrekkingsakkoord in werking treedt, blijft deelname van het Verenigd Koninkrijk aan het kaderbesluit nog mogelijk juist omdat aan voorwaarden zoals opgeworpen door Barnier is voldaan. Voor de periode daarna zullen de EU en het Verenigd Koninkrijk nadere afspraken moeten maken. De overeenkomst met IJsland en Noorwegen kan daarbij als voorbeeld dienen. Indien de EU en het Verenigd Koninkrijk zonder afspraken uit elkaar gaan, kan worden teruggevallen op het systeem van samenwerking tussen de ministers van Justitie op basis van het Europees Verdrag betreffende uitlevering van de Raad van Europa. 